\title{
Symptomatic Pulmonary Hypertension in a Child with Sickle Cell Disease
}

Karrie Villavicencio, MD, Dunbar Ivy, MD, Laura Cole, BSN, and Rachelle Nuss, MD Departments of Cardiology (K.D., D.I.) and Hematology/Oncology/Bone Marrow Transplant (R.N.) and the Colorado Sickle Cell Treatment and Research Center (L.C., R.N.), University of Colorado at Denver Health Sciences Center, Denver, CO

Only recently has it been appreciated that children with homozygous sickle cell anemia (SS) may have a clinically occult elevation of the tricuspid regurgitant jet velocity (TRJV). ${ }^{1}$ The case presented in this report demonstrates not only occult elevation of TRJV but that symptomatic SS-associated pulmonary hypertension may occur during childhood, masquerading as acute chest syndrome, and can be difficult to treat.

\section{CASE REPORT}

A boy was diagnosed with SS on newborn screening. By 5 years of age, he had 6 hospital admissions for presumptive reactive airway disease and 3 for acute chest syndrome. At 6 years of age, his pulmonary function tests revealed mild restrictive disease (forced vital capacity, $76 \%$ predicted) with early obstructive impairment (forced expiratory flow, $25 \%$ to $75 \%, 43 \%$ predicted) and responsiveness to a bronchodilator. Room air pulse oximetry was $99 \%$. Therapy for reactive airway disease was prescribed.

The child had a presumed fourth episode of acute chest syndrome at 7 years of age. At $71 / 2$ years, he presented with fatigue, tachypnea, chest pain, retractions, wheezing, hepatomegaly $(4 \mathrm{~cm})$, and pulse oximetry of $71 \%$ to $79 \%$. Hemoglobin and reticulocyte counts were baseline: $6.9 \mathrm{~g} / \mathrm{dL}$ and $39 \%$, respectively. Chest radiography revealed severe cardiomegaly and biventricular hypertrophy on the ECG. An echocardiogram showed mild biatrial, biventricular, and pulmonary artery dilation with a TRJV of $3.4 \mathrm{~m} / \mathrm{s}$ and estimated right ventricular systolic pressure of $50 \mathrm{~mm} \mathrm{Hg}$ on room air, reducing to $45 \mathrm{~mm} \mathrm{Hg}$ with oxygen. Oxygen, red cell transfusion, furosemide, bronchodilators, and nasal steroids were administered and at discharge, he was receiving $0.75 \mathrm{~L}$ oxygen continuously to maintain pulse oximetry $>90 \%$. Subsequent TRJVs, hemoglobin, reticulocyte counts, and treatment are shown in the Figure.

Two weeks after presentation, the TRJV remained elevated and pulmonary function tests showed forced vital capacity and forced expiratory flow $25 \%$ to $75 \%$, both $58 \%$ predicted, without response to albuterol. An evaluation to exclude thrombophilia revealed a normal protein C activity, free protein S, antithrombin III, vonWillebrand antigen and activity, and negative D-dimer. Prothrombin G20210A and Factor V Leiden mutations and antiphospholipid antibodies were absent. L-Arginine was prescribed at $4.5 \mathrm{~g} / \mathrm{d}(0.18 \mathrm{~g} / \mathrm{kg}$ per day) delivered as Arginaid (Novartis Oncology; East Hanover, NJ), and oxygen was continued. 
Four and one-half months from presentation, the TRJV remained elevated and a transcranial Doppler ultrasound showed a mean flow of $178 \mathrm{~m} / \mathrm{s}$ in the left middle cerebral artery. Therapy was commenced with monthly minor antigen-matched, red cell transfusions; hydroxyurea therapy was refused by the family.

One month after his first transfusion, the room air pulse oximetry was $91 \%$ and our patient was as active as his classmates, so only nocturnal oxygen was continued. The adenoids were removed for obstructive sleep apnea diagnosed by sleep study. The abdominal ultrasound showed a few gallstones, but, because he was asymptomatic, the family refused concurrent cholecystectomy.

Ten months from presentation, a TRJV could not be detected and arginine was discontinued. Due to difficulty suppressing hematopoiesis, transfusion therapy was intensified 1 month later, from $15 \mathrm{cc} / \mathrm{kg}$ of red cells every 4 weeks to every 3 weeks. He continued to present with low hemoglobin level, high reticulocyte count, and approximately $40 \%$ sickle hemoglobin. An evaluation for red cell antibodies was negative.

Sixteen and one-half months from presentation, the TRJV was again undetectable, our patient appeared well, and his mother ended transfusion therapy. About 2 months later, he presented with fatigue, chest pain, hepatomegaly, and a room air pulse oximetry of $80 \%$.

There was a brisk hemolytic anemia with a markedly elevated TRJV (Figure). Mild biatrial and left ventricular dilation $(5.43 \mathrm{~cm})$ were present. He was again treated with oxygen, red cell transfusion, diuretics, and steroids.

Results of right heart catheterization performed 1 month later and simultaneously obtained laboratory data are shown (Table). After catheterization, sildenafil (20 $\mathrm{mg} 3$ times daily) was added to the treatment regimen. Because of persistent elevation in TRJV and an ECG showing left ventricular hypertrophy with mild biatrial and left ventricular dilation, sildenafil was subsequently increased to $30 \mathrm{mg} 3$ times daily.

Twenty-nine months from presentation, 10 months from relapse, our patient appeared clinically well, but he had persistent mild biatrial dilation, left ventricular end-diastolic dilation $(6.13 \mathrm{~cm})$, and a TRJV unchanged from the time of right heart catheterization with a persistently elevated $\mathrm{N}$-terminal pro-brain natriuretic peptide. He had development of a red cell autoantibody (e) but continued with transfusions every 3 weeks.

\section{DISCUSSION}

Pulmonary hypertension has traditionally been defined as a mean pulmonary arterial pressure at right heart catheterization $\geq 25 \mathrm{~mm} \mathrm{Hg}$ at rest or $\geq 30 \mathrm{~mm} \mathrm{Hg}$ with exercise. However, Gladwin et $\mathrm{al}^{2}$ showed a TR jet of $\geq 2.5 \mathrm{~m} / \mathrm{s}$ on echocardiography was predictive of pulmonary hypertension on right heart catheterization in adults with SS and is associated with sudden death. They also showed an elevated $\mathrm{N}$-terminal pro-brain natriuretic peptide in adults is an indicator of risk for pulmonary hypertension-associated mortality. ${ }^{3}$ Further studies have confirmed that left ventricular diastolic dysfunction is also predictive of premature mortality in SS adults. ${ }^{4}$ Although our patient never had documented left ventricular dysfunction, he did have a persistently elevated N-terminal pro-brain natriuretic peptide, elevation of TRJV, and left ventricular dilation; however, their significance in childhood is unknown.

Similar to adults with SS, the etiology of pulmonary hypertension in our patient probably is multifactorial; reactive airway disease, obstructive sleep apnea, and recurrent acute chest syndrome are recognized risk factors..$^{5}$ Adults with SS-associated pulmonary hypertension 
may have hypoxemia secondary to sickle cell-induced pulmonary vascular and parenchymal injury, which is also true for our patient. ${ }^{6} \mathrm{~A}$ more recently appreciated factor predisposing to SS-associated pulmonary hypertension in adults with SS is hemolysis. Intravascular hemolysis leads to elevated plasma-free hemoglobin and release of erythrocyte arginase with secondarily impaired nitric oxide availability. Again, similar to adults with SS described with pulmonary hypertension, our patient had significant hemolysis, as indicated by marked anemia and elevated reticulocyte count, AST, LDH, plasma hemoglobin, and nitric oxide consumption. ${ }^{1,7} \mathrm{He}$ also had cholelithiasis, another hemolysis-associated complication described in adults.

Management guidelines for pulmonary hypertension recommend administration of hydroxyurea with or without erythropoietin, and, if not possible, long-term transfusion therapy. ${ }^{8}$ Due to initial maternal reluctance to any major intervention, and because arginine, a nitric oxide donor, has been shown to be efficacious in adults with SS and pulmonary hypertension, L-arginine was prescribed. ${ }^{9}$ We cannot assess our patient's response to arginine because red cell transfusions were started shortly thereafter. Hydroxyurea was not administered because of parental wishes.

Our case demonstrates that the pattern of hemolysis-associated complications, including pulmonary hypertension described in adults with SS, may occur during childhood. Right heart catheterization is an essential element of the evaluation for pulmonary hypertension, regardless of patient age, especially if the TRJV is $\geq 2.9 \mathrm{~m} / \mathrm{s}$. Our case also suggests that there may be a narrow window of opportunity for reversal of pulmonary hypertension as exemplified by our patient's need for daily supplemental oxygen for just 1 month initially but 6 months after relapse. TRJV normalization was observed within 6 months of transfusions initially but became refractory, even with the addition of sildenafil, after relapse. ${ }^{10}$ Ultimately, determination of preventive measures should lead to improved longevity for people with SS, but until then, safe, effective therapy for pulmonary hypertension must be defined.

\section{Acknowledgments}

The authors thank Dr Debbie Chen-Becker for initial data review and Dr Christopher Silliman for assisting with the Figure.

\section{Glossary}

\section{References}

1. Wang X, Tanus-Santos JE, Reiter CD, Dejam A, Shiva S, Smith RD, et al. Biologic activity of nitric oxide in the plasmatic compartment. Proc Natl Acad Sci U S A. 2004; 101:11477-82. [PubMed: 15258287]

2. Gladwin MT, Sachdev V, Jison ML, Shizukada Y, Plehn JF, Minter K, et al. Pulmonary hypertension as a risk factor for death in patients with sickle cell disease. N Engl J Med. 2004; 350:886-95. [PubMed: 14985486]

3. Machado RF, Anthi A, Steinberg MH, Bonds D, Sachdev V, Kato GJ, et al. N-terminal pro-brain natriuretic protein levels and risk of death in sickle cell disease. JAMA. 2006; 296:310-8. [PubMed: 16849664] 
4. Sachdev V, Machado RF, Shizukuda Y, Rao YN, Sidenko S, Ernst I, et al. Diastolic dysfunction is an independent risk factor for death in patients with sickle cell disease. J Am Coll Cardiol. 2007; 49:472-9. [PubMed: 17258093]

5. Hagar RW, Michlitsch JG, Gardner J, Vichinsky EP, Morris CR. Clinical differences between children and adults with pulmonary hypertension and sickle cell disease. Br J Haematol. 2008; 140:104-12. [PubMed: 17916102]

6. Machado RF, Gladwin MT. Chronic sickle cell lung disease: new insights into the diagnosis, pathogenesis and treatment of pulmonary hypertension. Br J Haematol. 2005; 129:449-64. [PubMed: 15877728]

7. Kato GJ, McGowan V, Machado RF, Little JA, Taylor J 6th, Morris CR, et al. Lactate dehydrogenase as a biomarker of hemolysis-associated nitric oxide resistance, priapism, leg ulceration, pulmonary hypertension, and death in patients with sickle cell disease. Blood. 2006; 107:2279-85. [PubMed: 16291595]

8. Castro O, Gladwin MT. Pulmonary hypertensionin sickle cell disease: mechanisms, diagnosis, and management. Hematol Oncol Clin North Am. 2005; 19:881-96. [PubMed: 16214649]

9. Morris CR, Morris SM Jr, Hagar W, van Warmerdam J, Claster S, Keptka-Lenhart D, et al. Arginine therapy: a new treatment for pulmonary hypertension in sickle cell disease? Am J Respir Crit Care Med. 2003; 168:63-9. [PubMed: 12626350]

10. Machado RF, Martyr S, Kato GJ, Barst RJ, Anthi A, Robinson MR, et al. Sildenafil therapy in patients with sickle cell disease and pulmonary hypertension. Br J Haematol. 2005; 130:445-53. [PubMed: 16042696] 

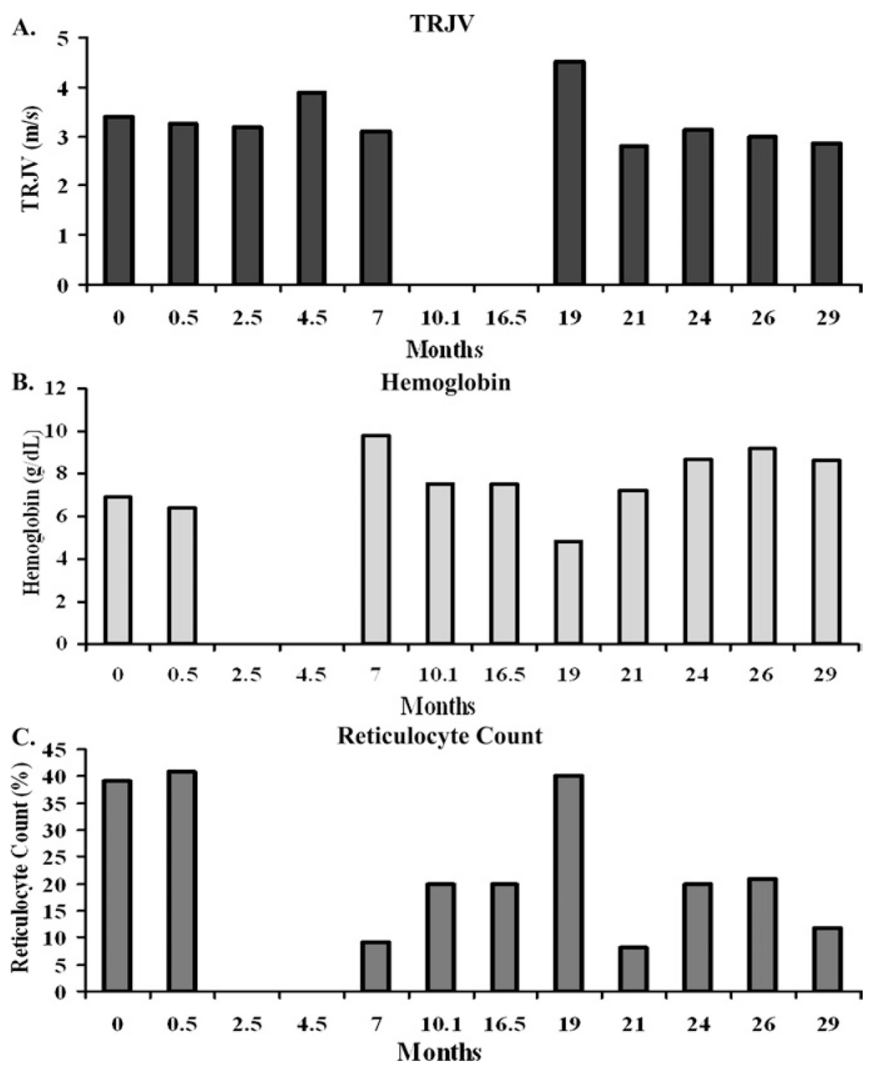

Figure.

Month and treatment are as follow: 0, red cell transfusion/continuous oxygen/ bronchodilators/Lasix/nasal steroids; 0.5 , begin arginine/continuous oxygen/stop bronchodilator and Lasix; 2.5, arginine/continuous oxygen; 4.5, arginine/begin red cell transfusion every 4 weeks; 5.5 , adenoidectomy; 10, stop arginine/red cell transfusion every 4 weeks; 11, begin red cell transfusion every 3 weeks; 16.5 , stop red cell transfusion; 19 , restart red cell transfusion every 3 weeks/continuous oxygen/furosemide/steroids; 21 , red cell transfusion every 3 weeks/continuous oxygen; 22, right heart catheterization/begin sildenafil $20 \mathrm{mg} 3$ times a day/every 3 weeks red cell transfusion/continuous oxygen; 24 , sildenafil $30 \mathrm{mg} 3$ times a day/every 3 weeks red cell transfusion/stop day time oxygen; 26, sildenafil $30 \mathrm{mg} 3$ times a day/every 3 weeks red cell transfusion; 29, same as 26 months. TRJV, Tricuspid regurgitant jet velocity. 


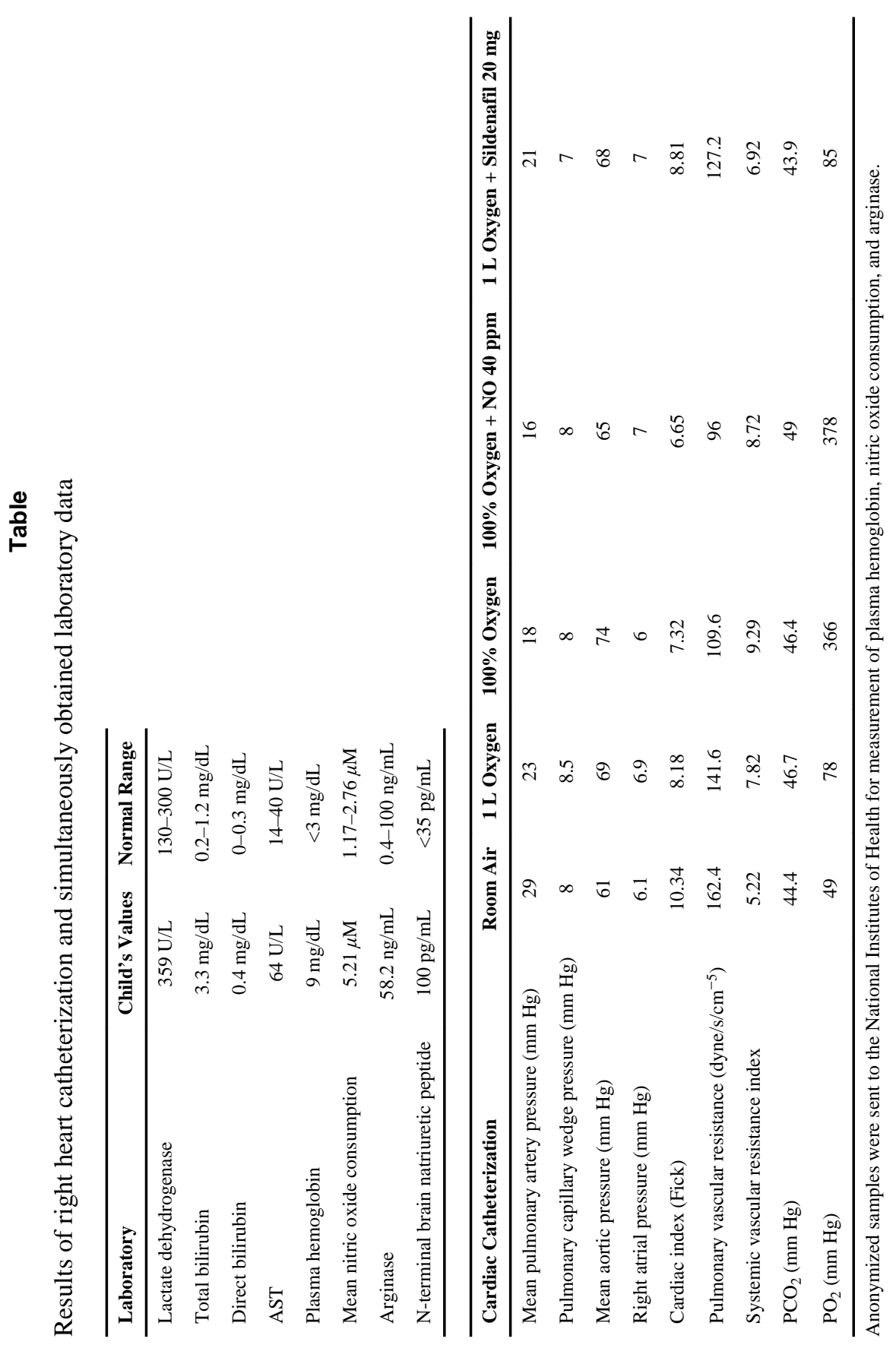

J Pediatr. Author manuscript; available in PMC 2011 July 1. 